International Journal of Health Sciences
Available online at www.sciencescholar.us
Vol. 6 No. 1, April 2022, pages: $68-80$
e-ISSN: 2550-696X, p-ISSN: 2550-6978
https://doi.org/10.53730/ijhs.v6n1.3236

\title{
Theoretical Foundations of Personification for University Educational Activities during Pandemic
}

\begin{abstract}
(1) crossanatik

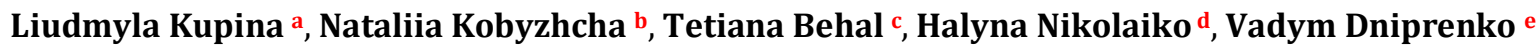

Manuscript submitted: 14 August 2021, Manuscript revised: 27 November 2021, Accepted for publication: 25 December 2021

Corresponding Author a

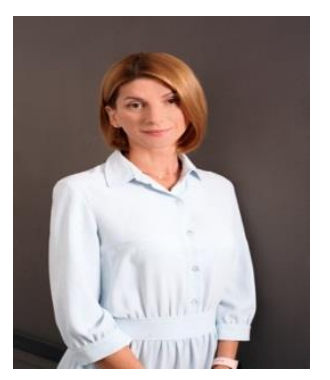

Keywords

distance education;

education system;

educational paradigms;

educational process;

higher education;

international pandemic; scientific methodological;

Abstract

The purpose of the article is to analyze modern literature in the direction of the personification of the educational process in Ukraine, to develop the theoretical foundations for the personification of the educational activities of the university in a pandemic using research methods were used to solve the set tasks: theoretical (study and analysis of scientific and pedagogical, psychological and pedagogical, reference, specialized literature, regulatory documentation on the topic of research, additional professional advanced training programs; analysis, comparison, classification of the information received and generalization); empirical (pedagogical experiment, observation, questionnaire survey, survey, conversation, testing) during an international pandemic. The article substantiates the concept of personalization of the educational process in higher education, indicates the place of personalization in some other definitions. Based on the analysis, an information model of the personalization of the educational process in higher education is proposed, socio-cultural prerequisites and methodological approaches to ensuring the personalization of the educational process in the university are disclosed, psychological and pedagogical features of the development of the individual in the educational process of the university are considered according to target (ideal) guidelines, the main technologies for personalizing the educational process are classified process in higher education.
\end{abstract}

International Journal of Health Sciences (C) 2022.

This is an open access article under the CC BY-NC-ND license (https://creativecommons.org/licenses/by-nc-nd/4.0/).

\section{Contents}

\footnotetext{
${ }^{a}$ National Pedagogical Dragomanov University, Kyiv, Ukraine

b Kyiv National University of Culture and Arts, Kyiv, Ukraine

c Kyiv National University of Culture and Arts, Kyiv, Ukraine

d Kyiv National University of Culture and Arts, Kyiv, Ukraine

e Kyiv National University of Culture and Arts, Kyiv, Ukraine
} 


\begin{tabular}{|c|c|c|}
\hline \multicolumn{2}{|c|}{ Abstract.... } & 68 \\
\hline 1 & Introduction & 69 \\
\hline 2 & 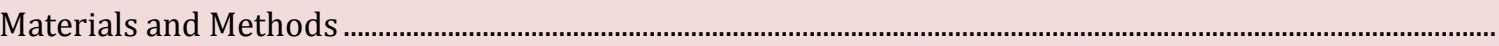 & 70 \\
\hline 3 & 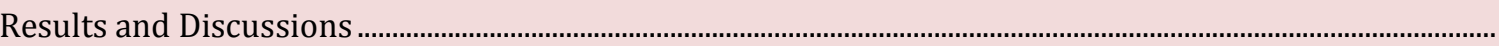 & 77 \\
\hline 4 & Conclusion & 78 \\
\hline & 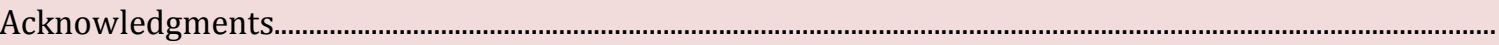 & \\
\hline & 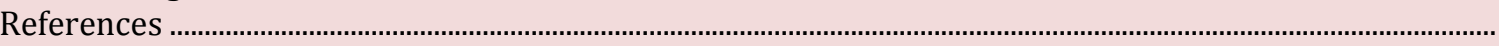 & \\
\hline & Biography of Authors & \\
\hline
\end{tabular}

\section{Introduction}

The modern world is characterized by the unrestrained growth of imbalances and contradictions, which intensify and reach a critical mass in the course of globalization and informatization, going under the sign of a destructive consumer-wasteful dominance of existence. Prominent scientists and thinkers of our time note that man and the social world today find themselves drawn into the devastating rhythm of the culturedissolving everyday life of utilitarian-technocratic life, devaluing humanistic values and moral norms. Society is increasingly losing its unity and significance as the leading formation of the personality.

In the existential dimension, there is a threat of dehumanization of a person, a threat of dissolution, and the depersonalization of a society devoid of moral foundations. Along with this, the growth of injustice and asymmetries in the world creates a global challenge of new confrontations and a growing global conflict. Progressive thought today dictates the vital need for a person to get out of the dissolved mass-individual state, to gain spiritual and moral integrity, and, in this regard, education can make its healing contribution (Rovai, 2003).

At the same time, education itself and higher education, in particular, is experiencing the influence of a general crisis that has engulfed the main educational and social institutions - family, school, law, morality, religion, social movements, parties, etc. This crisis is noted in all developed countries of the world and is due to deeper cultural reasons (Boling et al., 2012). First of all, there is a clear value-semantic reversal of consciousness in modern everyday life, when everything that was once forbidden becomes accessible, condemned by the encouraged, cherished by the banal, distant close, hated by the tolerant. In the vocabulary of modern "humanitarians" such imperatives as wisdom, truth, honor, dignity, conscience, goodness, goodness, justice are less and less common. These once leading values are tacitly announced as the old score for the play of civilization played. In their place comes a more convenient, economical, and lightweight "cultural package" of awareness, tolerance, political correctness, productivity, loyalty, sociality, adaptability, etc. At present, in scientific developments devoted to the problems of higher education, it is difficult to find a job in which a personality or personality-oriented approach would not be present as a methodological or theoretical basis.

However, in reality, the educational practice that is developing in higher education today is still far from the ideals of full-fledged personal growth of students. And in addition to the well-known reasons associated with the costs of the mass, flow-rate system of higher education, as well as its denationalization, commercialization, etc., it is obvious that there are still insurmountable barriers and shortcomings in the theory, methodology, and philosophy of higher education, including and in setting a personality-oriented approach (Howell et al., 2004; Widana et al., 2021).

Today, the catalyst for the development of progressive pedagogical and didactic concepts in the world is one idea - education should stop preparing a person for external needs (production, economics, science, politics, etc.), it should ensure the survival of the person himself, that is, turn to the problem of becoming human in man. A person should initially become a person, and then a professional, a specialist (Harris \& Sutton, 1986; Herliah et al., 2022).

Meanwhile, the existing paradigm of higher education implements for the most part a mechanistic (linear, simplified-unambiguous, predetermined) model of the development of science and society. The dominant technocratic consciousness in education practically leaves aside the emotional-sensual, moral side of the personality structure. It is no coincidence that the main vector of the development of science and education is seen by many scientists, first of all, in the humanization of new possible educational paradigms, in the center

Kupina, L., Kobyzhcha, N., Behal, T., Nikolaiko, H., \& Dniprenko, V. (2022). Theoretical foundations of personification for university educational activities during pandemic. International Journal of Health Sciences, 6(1), 68-80. https://doi.org/10.53730/ijhs.v6n1.3236 
of which is a person in his full-scale dimension (body, mind, emotions, soul), as well as his environment, both natural and created by man himself - material and social. Today there is a need for a comprehensive study of the phenomenology of the personal formation of a person in the space of higher education based on integrating social and humanitarian knowledge into the general field of science about modern education.

In general, the analysis of the existing situation in society, on the labor market, in the theory and practice of higher education reveals the existing objective contradictions between the need to strengthen the cultureforming, personality-forming role of higher education and the capabilities of universities; between the necessary and the real level of theoretical elaboration of the foundations of the educational process in modern conditions. The above circumstances led to the appeal to the present research topic, the problem of which is formulated as follows: what starting positions of pedagogical science can be considered as the theoretical foundations of the personalization of the educational process in higher education?

\section{Materials and Methods}

Today, in the context of global informatization, information increasingly replaces knowledge, a person is increasingly transforming into an unsaturated consumer of this information, and society - into a global market for information services. At the same time, the sphere of education also falls into the category of the latter.

The picture of the information society is increasingly associated with information absorption of personality and culture, more and more appears as an abyss of semantic devastation when the world turns into a giant informational cauldron, in which the "supporting structures" of society and different cultures are melted, differences are erased and the many-sided world turns into a uniformly faceless a mass of desocialized individuals, constantly thirsting for "information injections" (Iasechko et al., 2021).

The ongoing global processes of our time reinforce the problem of human alienation in the context of the growing individualization of society. Such a society is characterized by a person's loss of control over most significant social processes, increasing uncertainty and his insecurity in the face of changes uncontrollable by him, as well as a person's desire to abandon the achievement of promising goals to obtain immediate results. This leads to the disintegration of both social and individual life. As a result, modern society and culture are deprived of the personal basis, which occurs due to the destruction of the necessary social "soil" for the formation of a person as a person.

Threats of depersonalization, alienation, erosion of culture, loss of values indicate that modernity is throwing an anthropogenic challenge - a challenge to the man himself as a phenomenon. In the situation of destruction and deconstruction of culture, the symbolic plan of the Good and all the leading ontological ideas, without which a person cannot live as a cultural being, disappears.

The image of a modern man is more and more identified with the image of a "man of transition" who has left the "coast" of the previous culture and has not yet discovered a new civilizational limit of his future "refuge". This is a human-challenger (accepting modern challenges), a human-choice (a being who chooses), a human-networker, a human-pontiff ("bringing bridges"), a human-navigator, etc. Scientists state that the world and man are in a "cultural pause". The way out of it is associated with the need for a new spiritual reformation, a new attempt at the historical unity of the world based on the reconstruction of the moral and humanistic image of man and society in the modern era of transition.

It is in this vein that the progressive role of education and higher education is viewed today, in which, first of all, a saving mission is seen. However, being an element of the contradictory social continuum of our time, higher education is also experiencing a deep crisis today.

In our country, this crisis is caused by the process of denationalization of the higher education system against the background of social stratification and instability. Among the leading factors that have shaken the formative-universal structure of higher education as a national institution are its rapid commercialization, regionalization, confessionalization, etc. The crisis of higher education is also associated with the fact that it has become more and more widespread and highly specialized. Some simplification and less labor-intensive training in higher education are noted. An ever narrower specialization has led to the fact that the share of people with a holistic worldview, thinking about the general meanings of being, has sharply decreased in society. All over the world, today higher education is losing its former formative role, looking for new dimensions of its identity in the realities of the modern world. In our country, the hopes of society are 
associated with the universalization of higher education, with the development of integrative socio-cultural functions of universities. However, the reform is carried out continues the line of liberating the state from education, and education from values. The reform boils down to abandoning domestic unique traditions and "pumping" certain standards into the domestic higher education institution that have not passed the cultural and national filtering. The idea of the reform is subordinated exclusively to the goals of financial support for individual universities and the training of a potentially competitive specialist, which gives reason to speak of "reform without a platform", without a distinct national idea and social order. Even the very large-scale definition of "reform", which carries a stable negative semantic load to Ukraine, is being replaced by a more modest "modernization". At the same time, in the discussion of the parliamentary majority party, the goal of education was defined as the preparation of a nationally oriented elite.

In general, the crisis of higher education is largely due to the general crisis of modern culture, which stems from the unification and segmentation (fragmentation) of the personality, from the deregulation and privatization of the process of its formation, from the denial of authorities, the polyphony of proclaimed values and the associated fragmentation of life that characterizes our world. ... Education, turned into a service sector, is no longer intended to develop, but can only satisfy. Thus, real education today is at the mercy of spontaneously acting forces and processes that are not adequately regulated by society.

Universities today are increasingly playing a new and unusual role for themselves as a temporary haven, a place of maturation for young people who are not fully demanded by culture and society, thus turning into "sediment tanks of socialization". Scientists also associate the decline in the influence of higher education with the decline in the prestige of science in society that took place in the XX-XXI centuries.

In general, the crisis of education is expressed in the fact that in the modern world the human in a person disappears, or, more precisely, does not become. A person becomes a person in the process of a complex, holistic educational process. However, modern culture does not provide the necessary knowledge about who exactly should be educated in the process of education, who exactly should a person become in the process of education. Philosophy and theory of education are faced with the unfamiliar and challenging task of analyzing a process of personality formation that is not initially oriented towards a predetermined goal and is represented by modeling without a clear vision of the model.

A real way out of the crisis is possible in the appeal of higher education in the educational process to the very personality of a person and in the shift of emphasis in the philosophy of education and private didactics to the awareness of the need for the intention "to learn to live with uncertainty." And here the very heterogeneity of the internal structure of universities (and especially universities), their diversity, and dissimilarity can become a great help. In a world where no one can foresee what kind of special knowledge may be needed tomorrow, the presence of many diverse ways of obtaining higher education and its various options is a necessary and sufficient condition for higher education to rise to meet the challenges of our time.

The education system needs today fundamentally new self-determination capable of returning it the status of one of the priority social institutions. For the sphere of education, it is not so much the problem of promoting and "introducing" new ideologemes that is crucial as the problem of changing human existence. And in this vein, fundamentalization and humanization of its content and technologies stand out among the priorities for the development of higher education (Granell et al., 2016; Ananda et al., 2022).

The prospects for the development of higher education open up through the diversification of the structure of educational programs, which enable everyone to build that educational trajectory that most fully corresponds to his educational and professional abilities. Today, only a well-educated person who can flexibly restructure the direction and content of his activities can be protected in social terms. Therefore, it becomes clear that there are no two identical formations, just as there are no two identical personalities, for each person is unique.

Historical and cultural analysis of the genesis of higher education made it possible to determine those socio-cultural and value parameters that provided society with the creation of a viable structure of higher education, in varying degrees adequate to the state and social needs of the time (from its prototypes to the present day). In this movement, a certain pattern is traced - higher education emerges and develops as the embodiment of the idea of personalization in the cultural and civilizational process.

The idea of personalization also acts as a socio-cultural pattern in the formation of the theory and practice of higher education, as evidenced by the history of the development of higher education both in our country and abroad. Since the time of Socrates, Plato, and Aristotle, it has become obvious that the main channel of the

Kupina, L., Kobyzhcha, N., Behal, T., Nikolaiko, H., \& Dniprenko, V. (2022). Theoretical foundations of personification for university educational activities during pandemic. International Journal of Health Sciences, 6(1), 68-80. https://doi.org/10.53730/ijhs.v6n1.3236 
process of education and upbringing is a certain "personified channel" of "teacher-student" relations in various socio-historical and ethnocultural modalities.

The idea of personalization is reflected in the formation of the leading innovative educational systems since progressive pedagogical thought at all times has sought to ensure that a person in these systems becomes the basis around which the entire pedagogical process is built. The movement towards the personalization of the educational process as an irreversible direction in the evolution of higher education is most characteristic and typical of the formation of classical European universities.

From the very beginning of their appearance, universities were established as some kind of autonomous communities, in which the main method of teaching and academic communication was carried out at the level of individual contact between teacher and student, "by word of mouth", at the level of contact of consciousness, personalities, worldviews, and life experience. At the same time, dialogue, academic discussions, disputes played an important role in the formation of true knowledge.

Before the creation of universities in Europe, there was already an ancient liberal educational tradition, in which the idea was put forward that any education a priori includes a deep, whole, and personal connection between teacher and student. The ancients, having shown an example of the personalization of education, left the necessary "civilizational baggage" as the basis for the development of higher education: first, in the form of a person, a picture of the world, cosmology, a society of citizens; secondly, in the form of the foundations of scientific and professional knowledge; thirdly, in the form of the foundations of the liberal traditions of education.

The birth of the European university in the Middle Ages was facilitated by the growing free craft spirit of Italian cities. Having revived and preserved the culture of urbanism and the legacy of liberal education, Italy became the fertile ground on which, in combination with the entrepreneurial spirit of medieval life, such a unique phenomenon as the university was able to "grow". And at this stage, the formation of education adequate to public needs is conditioned by a block of three factors: first, a cultural impulse arises here due to a rather organic and non-conflict affirmation of the Christian model of the world and man; secondly, in Italy, a rich cultural layer is preserved as a heritage of antiquity, revived by the development of crafts and trade in cities; thirdly, a liberal-democratic atmosphere is being established in these cities (Parikh \& Verma, 2002).

From the very beginning, universities have been not only educational centers. In European history, they have always been cultural domains, and their autonomy was a condition for the emergence of various options for a future civilization in them. In addition, the university itself emerges as a civilizational project of personalizing the experience of culture in the educational sphere. It is in this guise that European universities have tended to pass through time, carrying ineradicable, culture-forming components (Hodge et al., 2017).

A new impetus to the development of the idea of personalization of education is given by the philosophical thought of the Renaissance, which put forward the humanistic concept of education, including the philosophy of humanism as the basis for the spiritual, social, physical development of the individual. The analysis of historical experience made it possible to identify, among the leading macro-civilizational conditions for ensuring the personalization of the educational process in higher education, three determining factors:

- Firstly, the presence of a cultural impulse in the person of a socially conscious (national) ideaconstruction of society and man;

- Secondly, the presence of a cultural layer that supposes the development of sciences, arts, technologies, professions, traditions of social and humanitarian thought, etc .;

- Thirdly, the presence of a wide range of freedoms as opportunities for the implementation of constructive ideas, self-development, and self-realization, the deployment of creative experience.

In terms of content and terminology, these three "directions of growth" of higher education formed the basis of the concept of the "Big Three" developed in the study. This definition was given due to the large cultural capacity and the semantic load of the selected factors. Briefly, factors can also be designated as key sociocultural phenomena - idea, science, freedom. The presented construction of three macro-factors acts as the initial socio-cultural matrix of the dynamic development of higher education.

In general, the historical and socio-cultural reconstruction of the genesis and formation of higher education allows us to state that its progressive development is associated with the implementation of the idea of personalizing the educational process (programs, content, methods, forms of education) through 
democratization, liberalization of education, increasing its component, cultivating an atmosphere of research creativity, scientific research, based on university autonomy in the face of three freedoms - freedom of management, teaching, and learning. Among the methodological approaches to ensuring the personalization of the higher education system, the personal approach, as well as culturological, axiological, synergetic, and hermeneutic approaches, stand out (Marhavilas et al., 2011).

The personal approach is the ethical basic personalization of the educational process in higher education. He proceeds from the premise that the genesis and development of educational systems are formed at the personal level and in the process of mutual activities of the personalities of the teacher and the student, standing on the relationship of trust, mutual respect, acceptance, cooperation. The culturological approach provides a spatial and environmental plan for the personalization of the educational process in higher education, considering education as a culturogenic process, i.e. from the point of view of socio-cultural development and personality formation. This approach is based on the fundamental position that personogenesis develops against the background of socio- and cultural genesis and represents culture as a special space for personalizing the educational process (Rodnyansky et al., 2021).

The axiological approach represents the value vector of personalization of the educational process. Within the framework of this approach, the process of personalization of education is presented as a value-semantic advancement of the individual, arising based on the student's internal intentions and aspirations, consisting in comprehending and subsequent translation of socio-cultural samples of self-determination (Martyniv et al., 2021). The essence of the personalization of the educational process within the framework of this approach is that any knowledge (information) that "falls" through training into the "field" of actions of the needs and life aspirations of a person is of a certain level of value for the student himself, his formation and development as a person.

The synergistic approach opens up an organizational mechanism for ensuring the personalization of the educational process, emphasizing its stochastic (probabilistic) nature. This approach makes it possible to expand the holistic understanding of personalization, as a self-organizing process, as a non-localized, intraindividual, open system, organically connected with scenarios for the unfolding of events in reality at the micro-macro- and mega-levels of personality existence.

The hermeneutic approach reveals the content side of the personalization of the educational process in higher education. It allows us to consider the content of education from the point of view of expanding the spheres of understanding of the student. This approach is centered on the need for personal explanation, interpretation, interpretation, found in any fact of a human appeal to knowledge and subsequent actions for its subjective processing. In the logic of this approach, personalization appears as a need, the desire of a developing individual to develop his language as an "element of transmission", to understand the culture and his "I" in it using mastering symbolic-sign models of explaining reality and achieving the foundations of the world outlook.

The problem of personalizing the educational process in higher education requires its own adequate psychological and pedagogical resolution. In this regard, the leading task is the need to rethink the goals of higher education based on understanding the phenomenology of personality formation in the educational process. First of all, the personality of the student in the dynamics of its development acts as the goal and the highest value of the educational process. The personal dimension, therefore, is the essence of the construction of the educational process, its theoretical foundations, and practice. The approval of a universal human component for educational purposes requires a different approach to the study of a person as a starting category for pedagogy. Ignoring this component is manifested in the formulation of the educational goal in impersonal, non-essential terms ("preparation", "readiness", "training", "good breeding", etc.).

Instead of functional study and training of a person (as a student, competitive specialist, scientist, etc.), it is necessary to study him himself, without predetermined boundaries and measures. Representing the goal of education as a "personality model" is also unproductive, since this inevitably leads to "fitting" real personalities to this model.

It is known that the nature of the personality limits the ability to influence it from the outside. Without the consent of the individual, it is impossible to determine what it should be. This explains the need for a humanitarian methodology of pedagogy, in which the categories of authorship, uniqueness, the subjectivity of the participants in the educational process, the dialogue of cultures, the aesthetic integrity of the universe, the

Kupina, L., Kobyzhcha, N., Behal, T., Nikolaiko, H., \& Dniprenko, V. (2022). Theoretical foundations of personification for university educational activities during pandemic. International Journal of Health Sciences, 6(1), 68-80. https://doi.org/10.53730/ijhs.v6n1.3236 
realization of the creative forces of a person who cognizes and transforms the world are affirmed and implemented.

The versatility of the category of personality is convincingly shown in the humanities. An example of this is the most valuable experience of cognition of personality, its phenomenology, accumulated within the framework of psychology. In particular, he points to the irreducibility and irreducibility of basic personal properties from the scope of only internal or only external determinants. Personality is a formation that arises in the unity of the counter-movement of society and the individual, in the existential integration of Culture and Human. Figuratively speaking, personality is the continuation of a person in culture, as well as the representation of culture in a person. The personality should be considered not as a system organized from elementary components, but as a single whole, as a universe that in no way decomposes into simple particles.

The personalization of the educational process assumes to consider the mechanisms and functions of a person's existence as an end in itself of education, the achievement of which is subordinated to its content and procedural components. We are talking about such manifestations as: reflection, meaning-making, selectivity, responsibility, autonomy, criticality, collision, motivation, mediation, orientation, self-actualization, selfrealization, ensuring the level of spirituality of life. In other words, in the structure of the educational process, there is a certain requirement or goal set from the outside; which, mediated by experience, is completed, enriched for each specific student. Only in this case does it become precisely the goal or the ideal reference point.

In general, in the context of personalization of education, a person is a person (student) who has his life history, is integrated into a certain cultural environment, has (already has) the properties of subjectivity and individual identity, self-actualizing in freely chosen types of life, in the process of self-development, search for meanings and their individuality. To build an educational practice in line with personalization, it is necessary to clearly understand the fact that a person himself creates a personality in himself, demanding that person that is characteristic only of him in culture.

The structure consists of three interconnected components.

The first component is the development of the value-semantic aspiration of the individual to achieve a subjectively significant and corresponding to the culture (profession, society) image of "I". Higher education should contribute to the actualization and building of students of a certain idea of their development and selfconstruction (dreams), sufficiently high, difficult, and attractive for the application of the student's efforts. This is the process of formulating personal goals, standards, expectations, and beliefs about oneself and one's capabilities to meet the requirements of society, cultural (professional) norms.

The second component is the development and expansion of the sphere of "I - competencies" of the individual. This component is pivotal from the point of view of self-realization of the student's personality as a subject with existing and expanding forces and capabilities. Personality development is presented as the development of I - competencies, i.e. opportunities to learn about the world and your "I" in it, build your system of relations with the world, and make your contribution to society and culture as a whole. The concept "I am competence" acts as a personal education that integrates knowledge, skill, understanding, and the ability to be creative in any area of human experience.

The third component is the development of internal responsibility. This component assumes the development of a sense of inner involvement of the individual not only in his business, study, work, profession, his "I", but also to other people, society, to the world as a whole. It is about the development of the moral principle and internal accountability of the student to himself for everything that he does, does or that happens to him in his life.

For the system of higher education, which is lining up in the mainstream of personalization, the presented components act as the initial tasks of the organization of education and the process of professional training. The experimental study carried out in this work has confirmed the need for personalization of education as the initial intention of building the learning process in higher education. In the course of the study, it was shown that the process of personalization of education at the university at the personal level is associated with the process of self-realization of students and is reflected in the characteristics of their "I - concept". These features are represented in various spheres of self-presentation and self-experience of students (needmotivational, cognitive, emotional, semantic) (lasechko et al., 2021).

In this study, we considered the concept of "I - concepts" as a system of "I - images" that is formed in the process of socialization, in which subjectively significant aspects of the experience of self-knowledge and self- 
experience of the individual result. This system serves as internal support for the individual for building basic relationships with the world and others, as well as developing a strategy for behavior in life.

A positive, holistic, diverse and consistent "I - concept" distinguishes individuals with a high level of development, able to successfully solve internal and external problems, think and act creatively. Negative, poor, inconsistent, and contradictory "I - concept" in many ways becomes an internal obstacle to the full and harmonious development of the individual. The experimental work was carried out in two stages.

- At the first stage, the features of the self-realization of students were identified.

- At the second stage, the features of the "I am the concept" of the students were analyzed.

During the first stage, according to the results of factor analysis, two factors were identified that determine the self-realization of students. We interpreted the first factor as a factor of the subjective significance of training. It reflected the subjective aspirations and beliefs of students to the overall value of education at the university. As the analysis has shown, the leading line here is the desire of students to give some semantic meaning to the actual life situation that develops in the conditions of university preparation - to realize their potential; to bring a dream closer, to benefit, to have a source of inspiration, etc.

The second factor was interpreted as a factor of social integration in learning. It reflects the plan of social conditions conducive to more successful self-realization in learning. The results indicate that the presence of social support and assistance, attention to the individual, the ability to participate in various events in the life of the university play a leading role here. The task of personalizing the educational process in higher education requires appropriate pedagogical conditions, the main of which are the following three: 1) the restructuring of the content of education, 2) the development of educational communications, and 3) the personalization of the professional activity of a higher school teacher (Iasechko et al., 2021).

Considering the restructuring of the content of education in line with its personalization, we mean the pedagogical process in the system of higher education, as a person's assimilation of the experience of culture with a clearly defined focus on expanding the sphere of "I - competencies"; acquisition of the semantic basis for professional self-development; as well as internal responsibility and author's position in the course of university preparation. In this regard, the content of education should operate with artifacts of social consciousness - the products of the experience of human thinking that have become the property of civilization. It should be expressed in the universal language of culture, expand the structure of knowledge, present samples and images of human experience, as well as the very images of a person as a person.

\section{The following are the main principles of personalization of the content of education.}

The principle of generalization and fundamentality of knowledge lies in the priority of deep theoretical and fundamental knowledge over-applied, empirical. This principle is aimed at the formation of a holistic systemic worldview of students, the development of broad erudition, and understanding of the foundations of the universe and human phenomenology.

The principle of the semantic orientation of the content of the training is to appeal to knowledge that introduces semantic order in the minds of students, giving answers to extremely existential questions - "What to strive for?", "For what to live?" We are talking about the representation in higher education of ontologicalsemantic, humanistic, universal-value knowledge, which makes it possible to overcome the curtain of pragmatism, utilitarianism in teaching and turn to the true meanings and essence of human existence in culture in the unified space-time dimensions of life.

The principle of the problematic nature of the content of education implies the concentration of knowledge around scientific, humanitarian, social, and other problems based on the development of intersubject connections. This principle orients the content of education towards the unity of the language and the didactic space of teaching, towards deep conjugation and interconnection of the learning process and mental activity of a heuristic nature.

The principle of openness of knowledge provides for the construction of the content of education at a university-based on the selection and presentation of knowledge in an open, probabilistic-stochastic, dialectical form, in their incompleteness and movement. This principle assumes the rejection of orthodox teaching schemes, from dogmatic, formal-mechanistic teaching in favor of a lively, creative appeal to the

Kupina, L., Kobyzhcha, N., Behal, T., Nikolaiko, H., \& Dniprenko, V. (2022). Theoretical foundations of personification for university educational activities during pandemic. International Journal of Health Sciences, 6(1), 68-80. https://doi.org/10.53730/ijhs.v6n1.3236 
experience of culture in teaching to solve the urgent problems of human existence in the modern world, the development of science, technology, and the professional development of the individual.

The principle of the constructiveness of knowledge assumes the formation of the content of education at the expense of knowledge that opens up real solutions and methods for solving urgent problems of a person in the modern world, problems of a scientific nature, and professional activity. This principle requires that knowledge be aimed not at expanding entropy and replicating uncertainty, but at increasing clarity in the outlook and self-consciousness of the student. Modern education is experiencing a deficit of such knowledge that offers, answers, shows perspectives that structure and lead thought to the resolution of existing contradictions of a natural, social, humanitarian nature.

The principle of humanization of the content of education assumes the need to humanize the content of education through the inclusion of knowledge, in the center of which is a person in his interaction with the natural and man-made world, a person in culture, society, in the universe. The humanization of education also requires knowledge that reveals ways of self-expression by a person of his integral essence, his selfrealization in space and time, ensuring the holistic development of students and orientation in the world from the standpoint of urgent tasks of human development and survival in the modern world (POLAT, 2021).

The principle of alternative knowledge in the content of education requires combining and offering students in equal proportions different approaches, concepts, scientific models, and explanatory constructions in understanding the leading problems of understanding the world, solving scientific, socio-cultural, professional problems. Teaching should operate with the knowledge that answers the same questions in different ways, building alternative models for explaining the essence of phenomena and processes. Such a construction of knowledge inevitably instills a culture of choice and acceptance of a conscious position, teaches to respect and take into account a different point of view, forms a broad outlook and a tolerant worldview.

The principle of flexibility and variability in the organization of the content of education assumes the formation of excess and varied composition of disciplines and courses to ensure the electiveness of learning. At the same time, a student should have the right and a real opportunity to design not only the learning space but also the time, the chronology of his progress in professional training, independently planning and setting the mode of training intensity, the rhythm of his educational load, the pace and timing of mastering disciplines and courses. The principle of a research orientation of the content of education assumes a high degree of familiarization of students with the knowledge, which introduces them into the circle of relevant and advanced scientific research, both of a fundamental methodological nature and an applied, constructive and technological order. This principle requires greater inclusion of knowledge that forms the basis of the organization of sciences and their research-heuristic potential. We are talking, first of all, about knowledge of the methodology of science, about familiarizing with the basics of activity to obtain new knowledge.

The transformation of the goals and content of education in line with the personalization of education in higher education requires an adequate restructuring of the educational space in the context of the development and expansion of the range of educational communications. By educational communications, we mean a connected set of methods, channels, techniques, modes, and formats for transmitting the necessary educational information related directly to the content of training and subordinate to the tasks of professional training at a university.

The real possibility of their intensification and personalization opens up through the informatization of the educational process based on the introduction of modern information and communication technologies. The development of educational communications should contribute to the cause of information unloading, the release of pedagogical resources for the establishment of real pedagogical communication, and interaction between teachers and students as subjects of the educational process (Nguyen et al., 2017).

The use of information technologies significantly expands the possibilities of presenting educational information, allows you to strengthen the motivation for learning, actively involve, immerse students in the educational process, expand the sets of applied educational tasks, increase self-control of educational activities, form students' reflection on their activities and open up new development opportunities. subject subject interaction in the educational process of the university. The versatile capabilities of information technologies allow them to be included as a teaching tool in almost all subjects and courses of study. 


\section{Results and Discussions}

Great prospects in this direction are opened by access to Internet resources, the organization of educational portals aimed at bringing information closer to the student's personality, creating conditions for the formation of truly open education at the university, which significantly expands the possibilities for versatile personalization of students' learning (Smith et al., 1999).

At the same time, the informatization of education inevitably requires a change in educational paradigms. The place of the old paradigm of one-directional subject-object learning should be replaced by a new paradigm of open developing and developing subject-subject education, in which the student and the teacher act as active participants in the educational process (Ankem, 2004). Organizationally and logically, in the new paradigm, all the necessary educational information is presented in an open, detailed form and is provided to the trainees at the beginning of mastering the corresponding disciplines and courses, and not in dosed - stepby-step portions during the training.

The development of educational communications based on information technology ensures the exit of the educational system of higher education to the design and implementation of an individual learning path. To successfully achieve this task, it is necessary to comply with the requirements of the following interrelated principles of personalization of educational communications:

- The principle of accessibility of educational communications requires the inclusion of each student in the process of free use of all information and educational opportunities and resources available to the university.

- The principle of interactivity provides for the ability to conduct information support in the mode of interactive dialogue, exchange of actions, and operations.

- The principle of the sensitivity of educational communications is that they must respond to the requests and needs of students for the introduction of appropriate changes by the research and teaching staff of the university.

- The principle of targeting educational communications assumes the correspondence of information support to the individual characteristics of students, their age-related cognitive capabilities, the level of training, professional specialization, and scientific interests.

- The principle of redundancy in educational communications assumes the possibility of a broad orientation and the collection of the necessary information, data, reference materials, etc. by students, allowing them to independently determine the set of conditions for solving the educational problem and fulfilling their request.

- The principle of the versatility of educational communications assumes the use of various information and communication teaching technologies: electronic textbooks and manuals, hypertext blocks, electronic libraries, reference books, encyclopedias, search engines, educational websites and portals, electronic journals, research publications, interactive video, multimedia training systems, virtual simulators, forums, conferences, etc.

- The principle of the integration of educational communications presupposes their direct integration into the educational system of the university, requires the construction of educational information based on interdisciplinary connections in large problem-thematic cycles that combine related courses and disciplines into single educational spheres.

- The principle of updating educational communications requires timely revision, correction, addition, updating of both the educational information itself and the methods of its presentation to the students.

- The formulated principles make it possible to approach the construction of the information and educational space of the university as a space for professional and cultural self-design and selfconstruction of the individual.

Kupina, L., Kobyzhcha, N., Behal, T., Nikolaiko, H., \& Dniprenko, V. (2022). Theoretical foundations of personification for university educational activities during pandemic. International Journal of Health Sciences, 6(1), 68-80. https://doi.org/10.53730/ijhs.v6n1.3236 


\section{Conclusion}

The defining pedagogical condition for the personalization of the educational process in higher education is the personalization of the teacher's activity. The provision of this condition is associated with the approval of the subject-phenomenological essence of teaching, carried out in the logic of constructing the author's pedagogical system. This system, in turn, grows based on the developed professional self-awareness of the teacher and is embodied in the practice of professional and pedagogical cooperation with students in the educational process of the university. The construction of the author's pedagogical system by the teacher presupposes his subjectivity and meaning-making in activities, which is expressed in an individual approach to setting goals, selecting the content of classes, developing means of creating a situation of personality development; the adaptability of the methodological system to their style characteristics.

Acknowledgments

We are grateful to two anonymous reviewers for their valuable comments on the earlier version of this paper. 


\section{References}

Ananda, A., Baso, Y. S., Hidayanty, H., Syarif, S., Aminuddin, A., \& Bahar, B. (2022). Providing education chronic energy deficiency (CED) uses web-based she smart to improve knowledge, attitudes, and practice in adolescent girls. International Journal of Health \& Medical Sciences, 5(1), 56-62. https://doi.org/10.21744/ijhms.v5n1.1833

Ankem, K. (2004). Adoption of Internet resource-based value-added processes by faculty in LIS education. Library \& information science $\quad$ research, 26(4), $\quad$ 482-500. https://doi.org/10.1016/j.lisr.2004.04.008

Boling, E. C., Hough, M., Krinsky, H., Saleem, H., \& Stevens, M. (2012). Cutting the distance in distance education: Perspectives on what promotes positive, online learning experiences. The Internet and Higher Education, 15(2), 118-126. https://doi.org/10.1016/j.iheduc.2011.11.006

Granell, C., Havlik, D., Schade, S., Sabeur, Z., Delaney, C., Pielorz, J., ... \& Mon, J. L. (2016). Future Internet technologies for environmental applications. Environmental Modelling \& Software, 78, 1-15. https://doi.org/10.1016/j.envsoft.2015.12.015

Harris, S. G., \& Sutton, R. I. (1986). Functions of parting ceremonies in dying organizations. Academy of Management journal, 29(1), 5-30.

Herliah, A., Baso, Y. S., Hidayanty, H., Syarif, S., Aminuddin, A., \& Bahar, B. (2022). Effect of web-based she smart education models on adolescent girl's knowledge, attitudes, and practice about obesity. International Journal of Health \& Medical Sciences, 5(1), 50-55. https://doi.org/10.21744/ijhms.v5n1.1832

Hodge, H., Carson, D., Carson, D., Newman, L., \& Garrett, J. (2017). Using Internet technologies in rural communities to access services: The views of older people and service providers. Journal of Rural Studies, 54, 469-478. https://doi.org/10.1016/j.jrurstud.2016.06.016

Howell, S. L., Saba, F., Lindsay, N. K., \& Williams, P. B. (2004). Seven strategies for enabling faculty success in distance education. The Internet and Higher Education, 7(1), 33-49. https://doi.org/10.1016/j.iheduc.2003.11.005

Iasechko, M., Iasechko, S., \& Smyrnova, I. (2021). Pedagogical aspects of self-development of distance learning students in Ukraine. Laplage em Revista, 7(Extra-B), 316-323.

Iasechko, M., Kharlamov, M., Gontarenko, L., Skrypchuk, H., Fadyeyeva, K., \& Sviatnaia, O. (2021). Artificial intelligence as a technology of the future at the present stage of development of society.

Iasechko, M., Shelukhin, O., Maranov, A., Lukianenko, S., Basarab, O., \& Hutchenko, O. (2021). Evaluation of The Use of Inertial Navigation Systems to Improve The Accuracy of Object Navigation. International Journal of Computer Science \& Network Security, 21(3), 71-75.

Marhavilas, P. K., Koulouriotis, D., \& Gemeni, V. (2011). Risk analysis and assessment methodologies in the work sites: On a review, classification and comparative study of the scientific literature of the period 20002009. Journal of Loss Prevention in the Process Industries, 24(5), 477-523. https://doi.org/10.1016/j.jlp.2011.03.004

Martyniv, L., Sokolova, A., Kurinna, S., Kopeliuk, O., Sediuk, I., \& Khomova, O. (2021). The modern problems and prospects of music formation and art education development during COVID-19. International Journal of Health Sciences, 5(3), 670-680. https://doi.org/10.53730/ijhs.v5n3.2936

Nguyen, A., Mosadeghi, S., \& Almario, C. V. (2017). Persistent digital divide in access to and use of the Internet as a resource for health information: Results from a California population-based study. International journal of medical informatics, 103, 49-54. https://doi.org/10.1016/j.ijmedinf.2017.04.008

Parikh, M., \& Verma, S. (2002). Utilizing Internet technologies to support learning: an empirical analysis. International Journal of Information Management, 22(1), 27-46. https://doi.org/10.1016/S02684012(01)00038-X

POLAT, E.S. (2008). Distance learning models.

Rodnyansky, D. V., Valeeva, G. F., Abramov, R. A., \& Makarov, I. N. (2021). Social determinants of human health: Quantitative and qualitative studies. International Journal of Health Sciences, 5(3), 649-660. https://doi.org/10.53730/ijhs.v5n3.2809

Rovai, A. P. (2003). In search of higher persistence rates in distance education online programs. The internet and higher education, 6(1), 1-16. https://doi.org/10.1016/S1096-7516(02)00158-6

Kupina, L., Kobyzhcha, N., Behal, T., Nikolaiko, H., \& Dniprenko, V. (2022). Theoretical foundations of personification for university educational activities during pandemic. International Journal of Health Sciences, 6(1), 68-80. https://doi.org/10.53730/ijhs.v6n1.3236 
Smith, B. R., Huff, D. S., \& Johnson, G. A. (1999). Magnetic resonance imaging of embryos: an Internet resource for the study of embryonic development. Computerized Medical Imaging and Graphics, 23(1), 33-40. https://doi.org/10.1016/S0895-6111(98)00061-5

Widana, I.K., Sumetri, N.W., Sutapa, I.K., Suryasa, W. (2021). Anthropometric measures for better cardiovascular and musculoskeletal health. Computer Applications in Engineering Education, 29(3), 550561. https://doi.org/10.1002/cae.22202

\section{Biography of Authors}

\begin{tabular}{|c|c|}
\hline & $\begin{array}{l}\text { Liudmyla Kupina } \\
\text { National Pedagogical Dragomanov University. Doctor of Law, Associate Professor, } \\
\text { Professor of the Department of Law and Branch Legal Disciplines of the Faculty of } \\
\text { Social Law. Areas of research interests: formation of professional speech of future } \\
\text { teachers; preparing students to develop skills of high school students. } \\
\text { Email: kupina@gmail.com }\end{array}$ \\
\hline & $\begin{array}{l}\text { Nataliia Kobyzhcha } \\
\text { Department of Information Technology, Kyiv National University of Culture and } \\
\text { Arts, Kyiv, Ukraine. Areas of research interests: formation of professional speech } \\
\text { of future teachers; preparing students to develop skills of high school students. } \\
\text { Email: kobyzhcha@gmail.com }\end{array}$ \\
\hline & $\begin{array}{l}\text { Tetiana Behal } \\
\text { Department of Museology and Examination Process of Historical and Cultural } \\
\text { Sites, Kyiv National University of Culture and Arts, Kyiv. } \\
\text { Areas of research interests: formation of professional speech of future teachers; } \\
\text { preparing students to develop skills of high school students. } \\
\text { Email: behal@gmail.com }\end{array}$ \\
\hline & $\begin{array}{l}\text { Halyna Nikolaiko } \\
\text { Department of Information Technology, Faculty of PR, Journalism and } \\
\text { Cybersecurity, Kyiv National University of Culture and Arts. Areas of research } \\
\text { interests: formation of professional speech of future teachers; preparing students } \\
\text { to develop skills of high school students. } \\
\text { Email: nikolaiko@gmail.com }\end{array}$ \\
\hline & $\begin{array}{l}\text { Vadym Dniprenko } \\
\text { Department of Information Technologies, Kyiv National University of Culture and } \\
\text { Arts, Kyiv. Areas of research interests: formation of professional speech of future } \\
\text { teachers; preparing students to develop skills of high school students. } \\
\text { Email: dniprenko@gmail.com }\end{array}$ \\
\hline
\end{tabular}

